\title{
Article \\ Forced Triboelectrification of Fine Powders in Particle Wall Collisions
}

\author{
Leonard Hansen ${ }^{*}{ }^{\dagger}$, Martin Weers ${ }^{\dagger}$, Annett Wollmann and Alfred P. Weber
}

check for updates

Citation: Hansen, L.; Weers, M.; Wollmann, A.; Weber, A.P. Forced Triboelectrification of Fine Powders in Particle Wall Collisions. Minerals 2022, 12, 132. https://doi.org/ $10.3390 / \min 12020132$

Academic Editors: Chiharu Tokoro, Shigeshi Fuchida and Yutaro Takaya

Received: 7 December 2021

Accepted: 20 January 2022

Published: 23 January 2022

Publisher's Note: MDPI stays neutral with regard to jurisdictional claims in published maps and institutional affiliations.

Copyright: (c) 2022 by the authors. Licensee MDPI, Basel, Switzerland. This article is an open access article distributed under the terms and conditions of the Creative Commons Attribution (CC BY) license (https:/ / creativecommons.org/licenses/by/ $4.0 /)$.
Institute of Particle Technology, Clausthal University of Technology, 38678 Clausthal-Zellerfeld, Germany; martin.weers@tu-clausthal.de (M.W.); annett.wollmann@tu-clausthal.de (A.W.); weber@mvt.tu-clausthal.de (A.P.W.)

* Correspondence: leonard.hansen@tu-clausthal.de

+ These authors contributed equally to this work.

Abstract: Triboelectric separation as an inexpensive and environmentally friendly technique could contribute to material-specific sorting. However, the application as a widespread method is limited due to the complexity of the process. In particle wall collisions, various parameters like collision energy and angle, work function of the contact partners, humidity, surface roughness, etc. influence the particle charging in a hardly predictable way. This study investigates the possibilities of forced triboelectric particle charging by applying an electrical potential to the metal contact partner (copper/steel pipe). The variations included different pipe lengths $(0.5 \mathrm{~m}-3 \mathrm{~m})$, particle materials, and particle sizes for limestone. A distinction is made between the net charge of the particles and the positive, negative, and neutral mass fractions. The work functions of the investigated materials vary from about $3.2 \mathrm{eV}$ to $>8.5 \mathrm{eV}$ for glass, limestone, artificial slag, and lithium aluminate particles. With the applied high-voltage potential, the particle net charge can be shifted linearly. For limestone, it is shown that the neutral fraction is highest at the Point of Zero Net Charge (PZNC). This observation may identify an approach for the material selective separation of one target component from a multi-material mixture.

Keywords: triboelectric; bipolar charge; sorting; minerals; fine powders; recycling

\section{Introduction}

The phenomenon of triboelectric charging has been known for a long time. It can have disastrous effects, such as high-voltage discharges and dust explosions, but also offers a number of useful applications, such as in triboelectric nanogenerators (TENG) [1-4] and in separation techniques. Triboelectric separation is industrially employed in mineral processing, mostly for separating two components from each other, such as feldspar from quartz [5], carbon from ash coal [6], or calcite from quartz [7]. The benefits of easy operation, low-energy consumption, and no uptake of water and chemicals are offset by the challenges regarding a limited understanding of the particle charging behavior, where the standard triboelectric series can only be used as a rough orientation [8]. For Engineered Artificial Minerals (EnAM) particles, i.e., slags encountered in the recycling processes within circular economy, this challenge becomes even more demanding due to the broad mix of components (e.g., recycling of lithium-ion batteries). Therefore, an improved understanding of the triboelectric charging and specific manipulation of the particle charge is needed for an improved separation process. The triboelectric charging depends on a large variety of influencing parameters related to the materials used (work functions, humidity, adsorbates, chemical surface modifications, surface curvature, surface roughness, etc.) and on the way of contacting the two surfaces (number, intensity, and duration of contacts) that themselves may depend on the environmental conditions such as relative humidity [9-11] and temperature $[12,13]$. 
The term triboelectric charging (or frictional electrification) is used in a broad sense to account for the transfer of a charge when two materials come in contact (as charge separation or charge transfer) [14]. Three general types of contact charging can be differentiated: the contact between two conductive materials (metals) [15], the contact between a conductive and insulating material [16], and the contact between two insulators [17,18]. Additionally, it can be distinguished between the charge transfer by electrons [15], ions [19,20], or material [21,22]. In the case of ion transport, charging occurs by the exchange of ionized surface adsorbates (i.e., dissociated water species) and surface stabilizers originating from the powder production [23]. However, in the present study, only dried powder and dried air was used in the experiments. Therefore, the ion transfer mechanism was supposed to be of minor significance. The experiments showed that material transfer depends on the mechanical properties of the materials, such as hardness, cohesive energy, and mode of contact $[22,24,25]$. To account for the complexity of the combined ion and mass transport, the so-called mosaic charge model was introduced [26]. According to Flachberger, there was no consensus on the tribocharging mechanism of mineral powders, but it seems obvious that the insulator charging behavior is determined by the surface properties and that more than one mechanism is active. However, since, in this study, the focus is on the adjustment of the particle charge by forced tribocharging, the most accessible mechanism of electron transfer is considered.

While, in metal-metal contacts, electrons are transferred according to the work functions of the contacting metals from the partner with the lower to the partner with the higher work function, the situation for the contact of insulators with other insulators or metals is less clear. Here, the surface structure of a particle is of paramount importance, since the surface electronic states may only be generated by defects or impurities, which determine the so-called effective work function. It is important to emphasize that the electron transfer between an insulator and a conductor can only occur locally and is influenced by the local surface properties [23]. Among the different concepts for electron transfer [27], only the capacitor model is discussed here, since it relates directly to the approach taken in this study [28]. It states that the charge transferred between two surfaces is given by:

$$
\Delta q=k_{C} \cdot C \cdot \Delta V=k_{C} \cdot \frac{\varepsilon_{0} \cdot \varepsilon_{r} \cdot S}{z_{0}} \cdot \Delta V=k_{C} \cdot C \cdot\left(\frac{\Phi_{1}-\Phi_{2}}{e}+V_{e x}\right)
$$

where $k_{C}$ is the charging efficiency (depending on the collision energy, collision angle, deformation, etc.); $C$ the capacity; $\varepsilon_{0}$ the electrical permittivity of the vacuum; $\varepsilon_{r}$ the relative permittivity of the gas; $S$ the contact area; and $z_{0}$ the critical distance over which electrons can be exchanged. Neglecting the pre-charges and space charge effects, the potential difference $\Delta V$ contains the difference of the effective work functions $\left(\Phi_{1}\right.$ and $\left.\Phi_{2}\right)$ and an externally applied electric potential $V_{e x}$. In this study, this external potential is varied to control particle charging. A similar model was used by Ireland, calling it the Ohmic charging model [29].

The evaluation of Equation (1) requires the work functions of both contact partners. Several attempts have been made to order the work functions of different materials, resulting in the so-called triboelectric series. However, various partially contradictory series have been reported. Part of these discrepancies could be due to the different surface roughness of the contact partners, as recently highlighted by Zou et al. [8]. They eliminated the roughness influence by realizing conforming contacts using a liquid metal so that the intrinsic character of polymers for gaining or losing electrons was revealed [8]. For the used contact partners, the work function values differ within the literature, depending on the measurement technique and the origin of the sample (cf. Figure 1). Nevertheless, they should provide a rough estimate of the charging behavior. The lower part of Figure 1 shows the work function of the metal-contact partner used in the experimental setup, i.e., coiled pipes of copper or steel, whereas the upper part shows the work functions for the particle materials. Since the surface of copper is oxidized in air, the values for $\mathrm{CuO}$ and $\mathrm{Cu}_{2} \mathrm{O}$ are also given (all copper-containing species are indicated in green). 


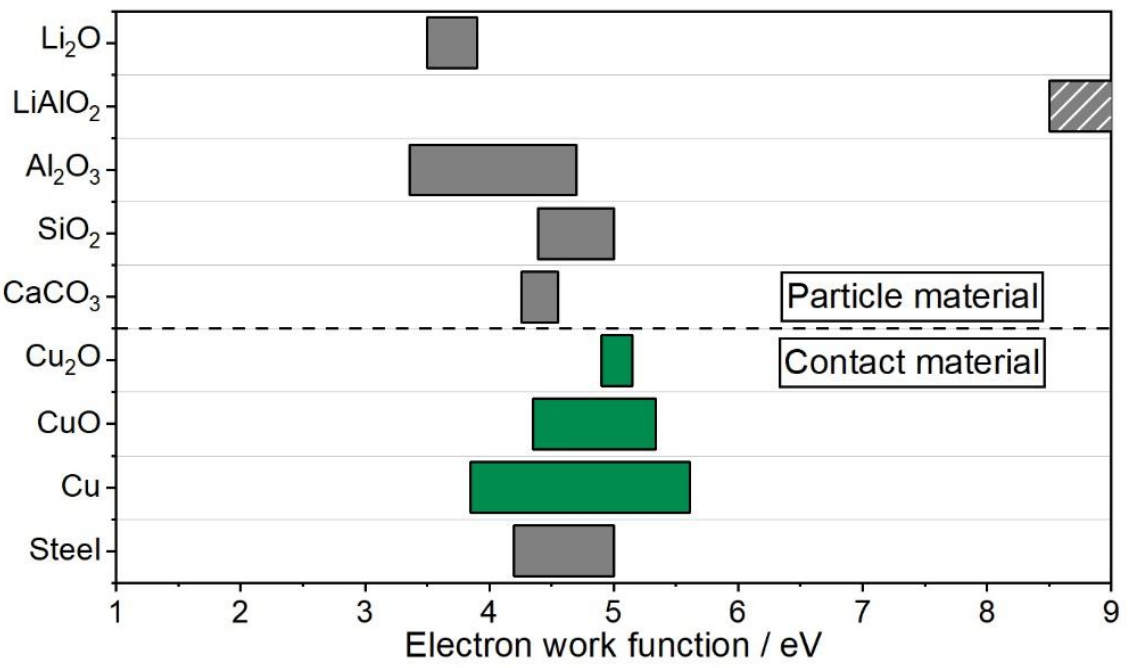

Figure 1. Overview over the different work functions of the used materials: $\mathrm{Cu}$ [30], stainless steel [31,32], $\mathrm{Al}_{2} \mathrm{O}_{3}[30,33], \mathrm{CaCO}_{3}[12,23], \mathrm{SiO}_{2}[12,30], \mathrm{LiAlO}_{2}$ (cf. Appendix A), and $\mathrm{Li}_{2} \mathrm{O}[34,35]$ (copper-containing species are indicated in green, and self-measured $\mathrm{LiALO}_{2}$ is indicated in grey with white stripes).

Essential for implementing an effective triboelectric sorting process with high separation sharpness is to minimize the mobility overlap, i.e., the overlap of the electrophoretic migration velocity of the different components. As the electrical mobility of the particles depends on their size and their charge, broad distributions in both parameters have to be avoided. In particular, bipolar charge distributions for particles of the same material make it impossible to achieve high-quality sorting. Many authors found such bipolar charging, e.g., References $[11,23,36]$, and it was also observed in our investigations for the triboelectric charging of calcite and talcum particles [37]. Several approaches were made to explain the bipolar contact charging of particles of the same material ranging from surface curvature effects on the work function [13] to the heterogeneity of the particle surface [38] and the material transfer during collisions [21].

However, even for powders exhibiting only one charge polarity, a phenomenon of equal mobility can occur, hampering the sorting of different materials. That means, e.g., a bigger particle with a higher electric charge can have the same mobility as a small particle with a lower electric charge, i.e., both particles migrate with the same velocity in an electric field, suppressing any (material-specific) sorting effect. While this phenomenon already represents a challenge for a two-component powder system, it becomes nearly unsolvable for systems composed of a large variety of different materials. The only fraction for which the equal-mobility problem and, in addition, the bipolarity problem does not play a role is the neutral powder fraction of the target material. Therefore, the objective of this work is to find triboelectric charging conditions, which move the highest share of the target powder into the neutral state.

While the understanding of the origin of the bipolar charge distribution is still under debate, a promising approach to shift the complete charge distribution was presented by Linsenbühler [39], as well as Oberrauner et al. [40]. They investigated the influence of high voltage applied to contacting surfaces [39,40]. The applied high voltage influences the average particle polarity. Linsenbühler's [39] results resembled a (inverse) zeta-potential curve, showing an isoelectric point. In contrast, Oberrauner et al. used an electric field between a PE-covered rotor (grounded) and covered stator (potential) as a tribocharging unit, varying the relative humidity from $20 \%$ up to $70 \%$ and the applied stator potential in a range of $-6 \mathrm{kV}$ to $6 \mathrm{kV}$. As the humidity increased, reflecting higher particle surface conductivity and gas conductivity, the accumulated particle charge decreased. Therefore, a lower potential is required to achieve a zero net charge of the used calcite particles. The modeling results of Shen [41] showed that the kinetics of electron reflux are slow, and fast 
separation of the contact partners results in a nonequilibrium state, where charges remain on the particles' surfaces. Increasing the moisture content may result in a faster electron backflow kinetic, which was also underlaid by the experimental results by Shen [41]. Decreasing the charge density is correlated with an increased relative humidity. Wang [42] investigated the contact charge transfer of glass material with different surface roughness. It was found that, in each case, the smoothest contact partner was more positively charged, whereas a higher roughness resulted in a negative net charge (glass-glass pairing). That indicates an electron transfer direction from the smoothest to the roughest material and might be a matter for the observed bipolar charging of identical materials.

Both investigations by Linsenbühler [39] and Oberrauner [40] provided persuading arguments to implement an external high voltage to adjust the particle charge and improve the triboelectric sorting process. In this work, nonconductive particles of different work functions are conveyed and specifically charged by helices subjected to high voltage. Special attention is also paid to the resulting influence on bipolar charging.

\section{Materials and Methods}

To get an overview of the experiments, this section introduces the used materials first. The experimental setups for triboelectric charging by a conducting coil and electrostatic separation for a more detailed investigation are described afterwards.

\subsection{Particulate Materials}

The particle materials used in the experiments with their main components are listed in Table 1. All particles except the glass spheres were produced by grinding.

Table 1. Properties of the used materials.

\begin{tabular}{|c|c|c|}
\hline Material & Supplier & Components \\
\hline Saxolith 8 & $\begin{array}{l}\text { Sh minerals GmbH, } \\
\text { Heidenheim, Germany }\end{array}$ & $\mathrm{CaCO}_{3}$ \\
\hline Saxolith 40 & $\begin{array}{l}\text { Sh minerals GmbH, } \\
\text { Heidenheim, Germany }\end{array}$ & $\mathrm{CaCO}_{3}$ \\
\hline Saxolith 70 & $\begin{array}{l}\text { Sh minerals GmbH, } \\
\text { Heidenheim, Germany }\end{array}$ & $\mathrm{CaCO}_{3}$ \\
\hline Lithium aluminate & $\begin{array}{c}\text { Sigma Aldrich, St. Louis, } \\
\text { MO, USA }\end{array}$ & $\mathrm{LiAlO}_{2}$ \\
\hline${ }^{1}$ EnAM slag & $\begin{array}{c}\text { Institute of } \\
\text { metallurgy-RWTH Aachen }\end{array}$ & $\begin{array}{c}2 \mathrm{X}_{2} \mathrm{SiO}_{4} \text { (larnit), (forsterit), } \\
\mathrm{CaAlSiO}_{4} \text { (melilit solid solution) } \\
\text { and } \mathrm{LiAlO}_{2}\end{array}$ \\
\hline Glass spheres & $\begin{array}{c}\text { Samore GmbH, Bindlach, } \\
\text { Germany }\end{array}$ & $\mathrm{SiO}_{2}$ \\
\hline Spodumene $\mathrm{LiAl}\left(\mathrm{SiO}_{3}\right)_{2}$ & $\begin{array}{l}\text { Börkley Keratech GmbH, } \\
\text { Berlin, Germany }\end{array}$ & $\begin{array}{c}65 \% \mathrm{SiO}_{2}, 26 \% \mathrm{Al}_{2} \mathrm{O}_{3} \text {, and } 7 \% \\
\mathrm{Li}_{2} \mathrm{O} \text { (supplier information) }\end{array}$ \\
\hline
\end{tabular}

${ }^{1}$ Engineered artificial minerals. ${ }^{2} \mathrm{X}$ may be calcium or magnesium.

In addition to pure minerals such as Saxolith or glass, complex material mixtures (spodumene or EnAM slag) are also used in experiments concerning future slag materials from recycling processes.

The cumulative particle size distributions of all the materials were measured with laser diffraction (HELOS ${ }^{\circledR}$, Sympatec $\mathrm{GmbH}$, Clausthal-Zellerfeld, Germany) using dry dispersion (RODOS ${ }^{\circledR}$, Sympatec $\mathrm{GmbH}$, Clausthal-Zellerfeld, Germany) and are given in Figure 2. The limestone was named Saxolith (or Sax) 2, 8, 40, and 70, and the corresponding measured medians were $3.5 \mu \mathrm{m}, 7.5 \mu \mathrm{m}, 50 \mu \mathrm{m}$, and $60 \mu \mathrm{m}$, respectively. These medians were used for all further calculations. 


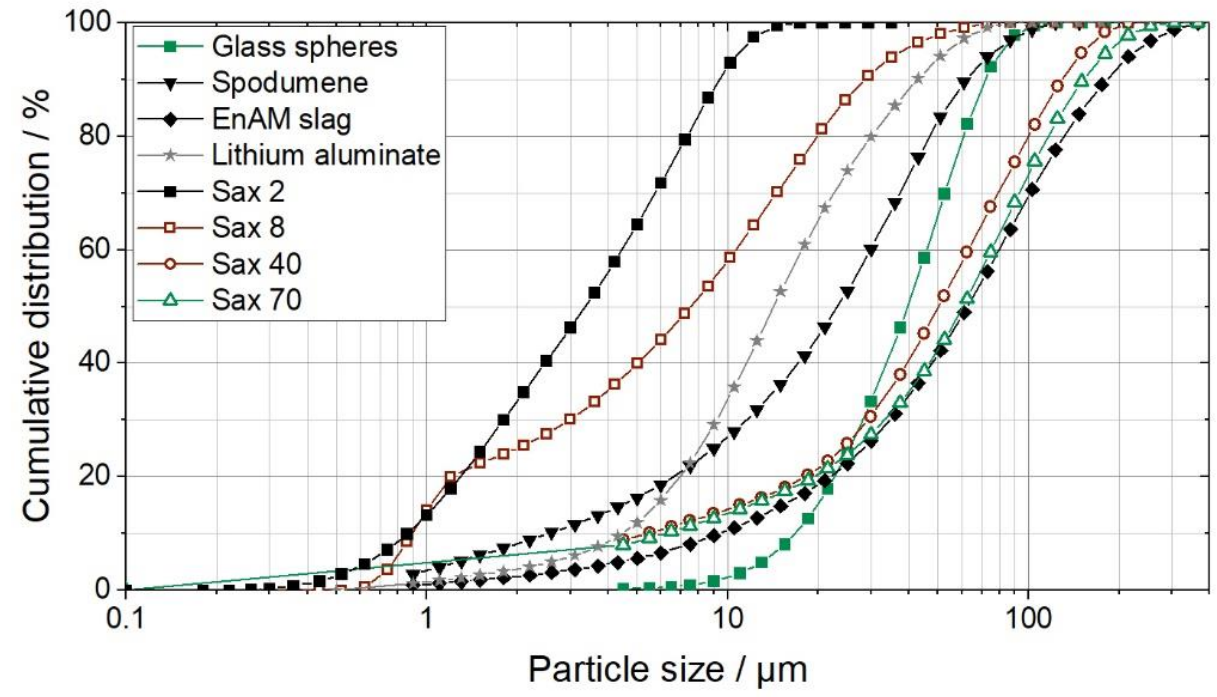

Figure 2. Cumulative particle size distributions $\left(\mathrm{Q}_{3}\right)$ of the used materials obtained with laser diffraction.

\subsection{Methods}

Figure 3 shows an overview of the experimental setups used to investigate the manipulation of the triboelectric charge. A screw conveyor feeds the particles in an electrically grounded dispersing unit (RODOS ${ }^{\circledR}$ —Sympatec, Clausthal-Zellerfeld, Germany), based on the injector principle and operated with $6 \mathrm{~m}^{3} / \mathrm{h}$ dried air as a dispersing gas and a particle mass flow of appr. $0.213 \mathrm{~g} / \mathrm{s}$ (e.g., Saxolith 70). The relative humidity in the setup was kept constant at $5 \%$ for all experiments. After the dispersion, the particles were passed through an insulating tube into a metal helix, connected to a high-voltage (HV) source, adjustable from $-30 \mathrm{kV}$ up to $+30 \mathrm{kV}$. Due to breakdowns at $-30 \mathrm{kV}$, the potential was varied between $-25 \mathrm{kV}$ and $+30 \mathrm{kV}$. The helix length can be varied from $0.5 \mathrm{~m}$ to $3 \mathrm{~m}$. As the helix materials, copper and stainless steel were used. The inner tube diameter was $10 \mathrm{~mm}$, and the bending radius was $15 \mathrm{~cm}$. A partial flow was sampled for the FCE and the electrostatic precipitator. All experimental results were the mean values of double determinations.

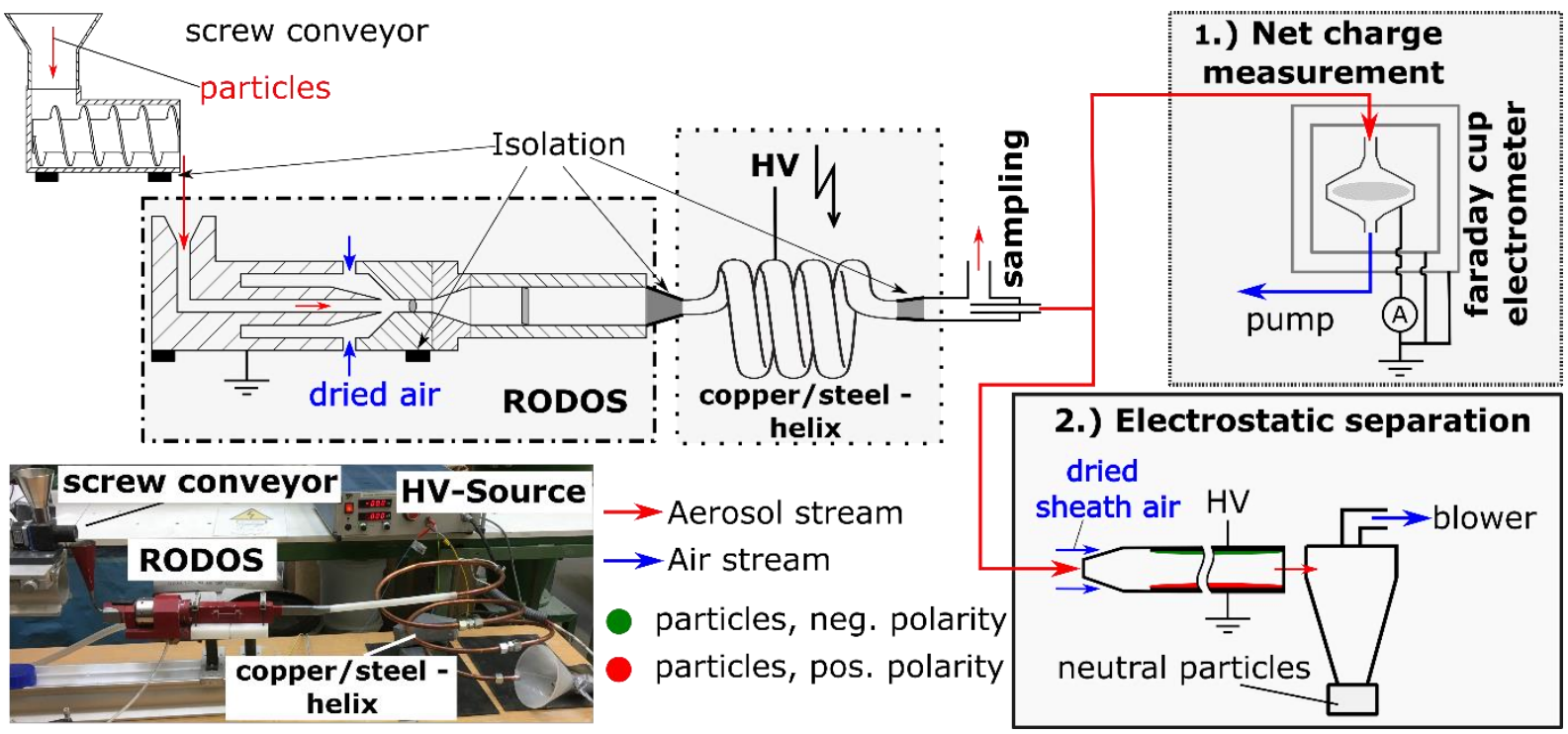

Figure 3. Experimental setup. The particles are suspended in a carrier gas (dried air) by a dispersing unit and charged by a copper or stainless-steel helix to analyze the (1) net charge and (2) charged and neutral fractions of the particles via an electrostatic precipitator. 


\subsubsection{Net Charge Measurements}

After the charging process, the net charge was measured with a Faraday cup electrometer (FCE). The electrometer (Keithley, model 6514, Cleveland, OH, USA) was connected to an isolated inner Faraday cup containing a particle filter holder enclosed by an outer Faraday cup to reduce the external interference with electromagnetic radiation. The charge per particle mass $(\mu \mathrm{C} / \mathrm{g})$ was determined from the measured current and the known particle mass flow rate.

\subsubsection{Electrostatic Separation}

An electrostatic precipitator with a turbulent flow $(\operatorname{Re}=11,700)$ as described in Hansen et al. [20] was used to quantify the charged and neutral fractions. The applied electric field was $2 \mathrm{kV} / \mathrm{cm}$. The charged particles were deposited on the electrodes due to their high electrical mobility, and the neutral particles were led into a cyclone at the end of the separator. In order to assure complete separation of the particles, the separation efficiency curve was determined in the preliminary experiments. The charged fractions were analyzed offline by pulling out the coated electrodes and sucking the particles onto filters for weighing.

\section{Results}

To get a rapid overview of the sensitivity of the triboelectric charging on different parameters (helix length, particle size, and particle material), the net charge of the powders was measured by an FCE as a function of the applied voltage. Finally, the electrostatic precipitator was used for more detailed investigations of the positive, negative, and neutral mass fractions for one material (Sax 8).

\subsection{Net Charge-Length Dependency}

Equation (1) suggests that applying an external electric potential to one contact partner can influence the triboelectric charging process. Figure 4 shows this behavior for limestone particles (Saxolith 8 ) by changing the applied potential on the copper helix. The points where $0 \mathrm{kV}$ is applied (grounded helix) represent pure triboelectric charging. For negative potentials and positive potentials up to $15 \mathrm{kV}$, the particles are charged negatively. At $15 \mathrm{kV}$, the particle charge switches to positive (cf. Figure 4a). This point is defined as the Point of Zero Net Charge (PZNC) in the following. The PZNC varies slightly for the different helix lengths, whereas the slope rises significantly with the increasing helix length. Due to more impacts in a longer helix, the charging efficiency rises, explaining the increase of the slope. As shown in the model of Matsusaka [28], the slope depends on the capacity (C) and charging efficiency $\left(\mathrm{k}_{\mathrm{c}}\right)$. The PZNC, however, remains virtually constant for a specific material, as expected from Equation (1). As Matsusaka pointed out, the particle impact frequency in a pipe remains constant; hence, the number of impacts is proportional to the pipe length. [28]. With Equation (2), the obtained charge growth in a pipe with the length $L$ and the characteristic length of particle charging $L_{0}$ can be calculated from the fit (see the table in Figure 4b) [28]. In the present case, the equation was modified, taking the applied external potential $\left(V_{e x}\right)$ into account. The initial particle charge without a helix was negligible (e.g., $0.3 \mu \mathrm{C} / \mathrm{g}$ for Sax 8).

$$
\Delta \bar{q}_{m}=\bar{q}_{m \infty} \cdot\left\{1-\exp \left(-\frac{L}{L_{0}}\right)\right\} \text {, with } \bar{q}_{m \infty} \sim \frac{S_{e f f}}{z_{0}} \cdot \Delta V \text { and } S_{e f f} \sim \frac{L}{L_{0}}
$$

where the maximum charge is $\bar{q}_{m \infty}$, the critical gap between particle and wall is $z_{0}$, and $S_{e f f}$ is the effective contact surface of the particle. 


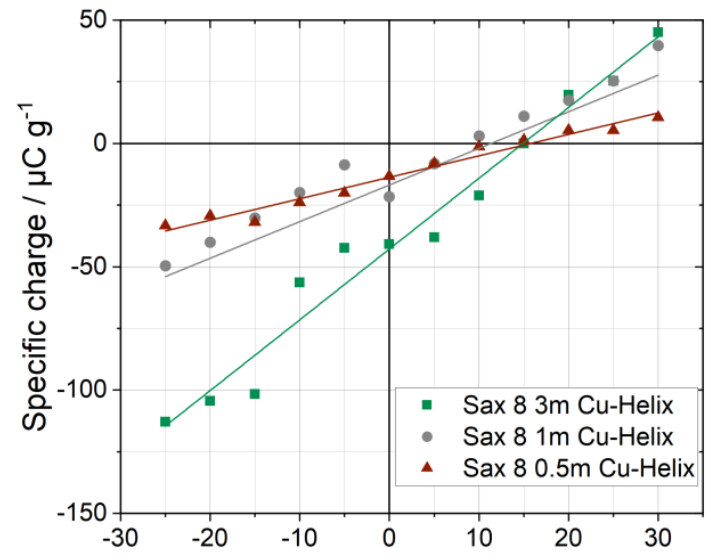

a)

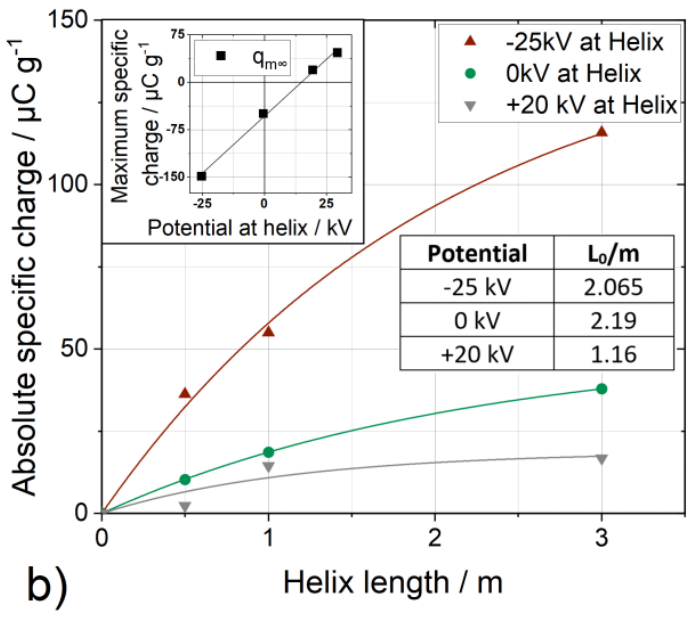

Figure 4. Specific net charge for different lengths and voltages (0.5-3 m) for limestone (Saxolith 8) with (a) constant lengths and (b) constant voltages.

After a certain number of collisions, the particles cannot acquire additional charges due to their limited capacity $\left(S_{\text {eff }}=S_{\text {Particle }}\right)$. Thus, Equation (2) generates a suitable fit for the measured data points in Figure $4 \mathrm{~b}$.

In the original publication of Matsusaka, $\Delta V$ (in Equation (2)) was only considering the difference of the work functions. However, Figure $4 \mathrm{~b}$ shows that the proportionality between $\bar{q}_{m \infty}$ and $\Delta V$ also holds true when including an externally applied potential to one of the contacting partners. This observation confirms the applicability of the plate condenser concept for an externally applied potential and extends the range of triboelectric particle charging (also mentioned by Matsusaka [43]), as further outlined below. The maximum value of the specific charge is changed by the applied voltage (insert Figure $4 \mathrm{~b}$ ), resulting in the same dependence of the applied voltage as the net charge but with a steeper slope. The PZNC (Figure 4a) and the characteristic length of particle charging (table in Figure 4b) can be very roughly assumed to be constant within the experimental uncertainties.

\subsection{Net Charge-Size Dependence}

In addition to the number of contacts (e.g., length of the helix), the collision intensity for different particle sizes may affect the extent of charging due to their different collision kinetics. Hence, the net charges of different limestone fractions (Saxolith 2, 8, 40, and 70) were measured as a function of the applied potential at constant helix length and volume flow rate (cf. Figure 5a). All Saxolith materials originated from the same open pit area, so that the materials hardly varied either in composition or in morphology.
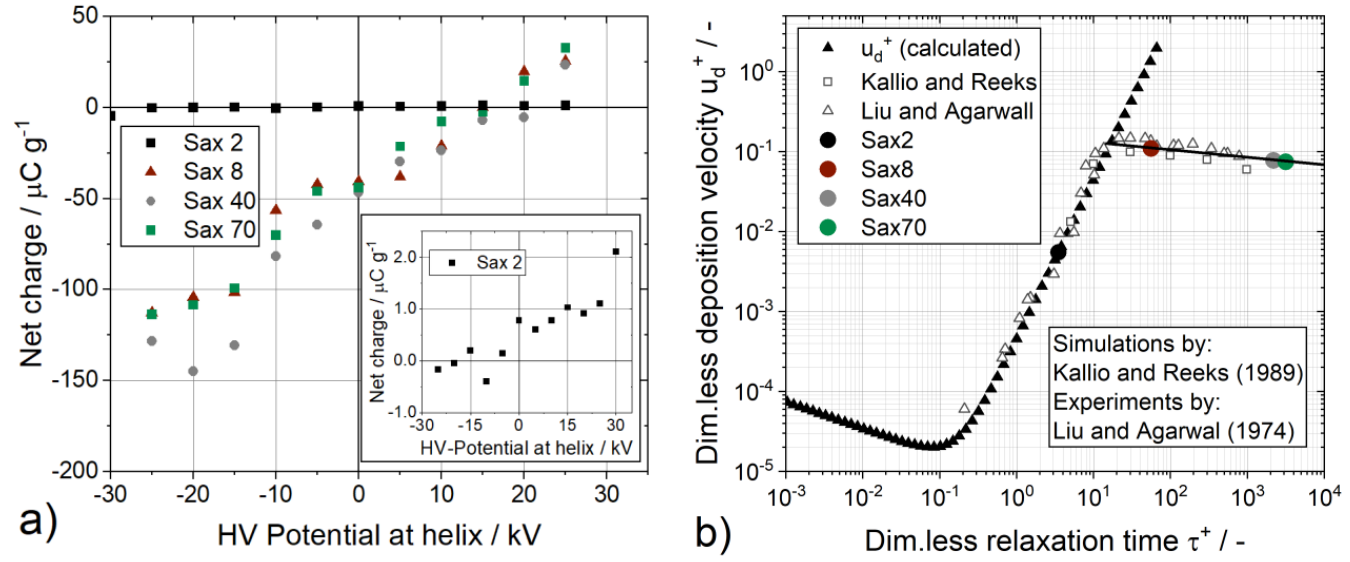

Figure 5. (a) Specific net charge per mass for different sizes of Saxolith (limestone) and varied 
potential at the copper helix; insert: zoom for Saxolith 2 particles. (b) Dimensionless deposition velocity vs. dimensionless relaxation time for turbulent deposition, calculated for Saxolith 2, 8, 40, and 70 particles and compared to the literature data [44,45] (calculation in Appendix B).

The slope of the mass-specific net charge vs. applied potential is found to be nearly constant throughout the particle sizes of Sax 8, Sax 40, and Sax 70, while Sax 2 shows a different behavior, as discussed below. The particle wall collision is assumed as a single Hertzian contact of a spherical particle to understand the constant slope. Then, the charge transferred between an isolating particle and a conducting wall (charge relaxation time $\tau_{e l}>>$ contact duration $\Delta t$ ) in a single collision can be calculated in the following way [46-48]:

$$
\begin{gathered}
\Delta q_{\text {single }}=\frac{\varepsilon_{0} \varepsilon_{r} S}{z_{0}} \Delta V \frac{\Delta t}{\tau_{e l}} \\
\text { with : } \Delta t \sim \frac{d_{p}}{u_{p}} \alpha ; S \sim d_{p}^{2} \alpha ; \tau_{e l}=\varepsilon_{0} \varepsilon_{r, p} \cdot \beta_{p} ; \alpha \sim\left[\rho_{p}\left(\frac{1-v_{p}^{2}}{E_{p}}+\frac{1-v_{w}^{2}}{E_{w}}\right)\right]^{\frac{4}{5}}
\end{gathered}
$$

where $v_{p}, v_{w}, E_{p}$, and $E_{w}$ are the Poisson ratio and the Young modulus of the particle or wall, respectively. Furthermore, $\mathrm{z}_{0}$ is the critical gap between the particle and the wall, $u_{p}$ is the particle velocity, and $S$ the surface of the particle in contact with the wall. The electrical relaxation time is $\tau_{e l}$, and the electrical resistivity of the particle material is $\beta_{p}$.

However, the number of collisions must be known to compare the totally transferred charge along the helix (Equation (1)) with the transferred charge in a single collision (Equation (3)). As an approximation, the concept of turbulent deposition in a fully developed turbulent pipe flow can be employed. Here, the deposition rate (also called deposition velocity) is calculated from the particle flux towards the wall and the particle number concentration outside of the viscous sublayer [49]. According to Liu and Agarwal [44], the deposition velocity as a function of the dimensionless aerodynamic relaxation time $\left(\tau_{\mathrm{ae}}{ }^{+}\right)$ increases first in a quadratic manner (calculated by Equations (A1)-(A3) - Appendix B) and later reaches a plateau (cf. Figure 5b). The dimensionless relaxation time is the ratio of the particle stop distance to the characteristic turbulence length. Regarding the turbulent flow in the helix, the flow field can be assumed to be fully developed but becomes more complicated compared to a straight tube, since, additionally, Dean vortices occur. Due to the comparable curvature of the pipe, Reynolds numbers, and Stokes numbers, the work of Noorani et al. [50] can explain the occurrence of Dean vortices in the applied setup of this work. The simulations revealed that the higher the Stokes number or the tube curvature, the more the particles followed the Dean vortices within the pipe on a macroscopic level but experienced inertial effects on a microscopic level, leading to wall collisions.

However, in a first approximation, the situation in the viscous sublayer remains unchanged when comparing straight tubes with helical tubes. Transferred to the limestone particles considered here, Sax 8, Sax 40, and Sax 70 are located on the plateau of a constant dimensionless deposition velocity of approximately 0.1 (Figure $5 \mathrm{~b}$ ). Therefore, the experimentally found constant ratio of transferred charge and particle mass for particles $\geq 8 \mu \mathrm{m}$ is a consequence of the same particle collision rate with the wall, independent of the particle size in this size range. The smaller particles (Sax 2) have a lower deposition velocity of 0.01, meaning that the particle wall collisions decrease drastically, resulting in a lower particle charge, as shown in the insert of Figure 5a. For particles larger than $40 \mu \mathrm{m}$, it is expected that the deposition velocity drops again, as already implied in the behavior of the $70-\mu \mathrm{m}$ particles. Nevertheless, the observed net charge of the $70-\mu \mathrm{m}$ particles is nearly the same as for the $8-\mu \mathrm{m}$ and $40-\mu \mathrm{m}$ particles. This result may be due to an accumulation of charged particles in turbulent flows near the walls, as Li et al. [48] reported. On the other hand, for particles much smaller than $8 \mu \mathrm{m}$, a reduction of the deposition velocity is expected. It needs to be emphasized that the width of the particle size distributions (especially broad for Sax 8) may smear out size-dependent charging effects to a certain extent. Nevertheless, for Sax 2, which also exhibits a broad size distribution, a low net charge is observed, presumably due to the low deposition velocity. 
The observed phenomenon also provides an indication for the range of applicability of the realized forced triboelectric charging in a helix. Small particles, typically in the submicron range, will not collide with the wall of the helical tube at all, except for diffusional transport, which is rather slow and is not expected to contribute significantly to the charging. Thus, the method might not be applicable for very small particles. For large particles, i.e., above a few $100 \mu \mathrm{m}$, their radial acceleration is rarely sufficient to penetrate the viscous sublayer. These particles are preferentially entrained with the carrier gas in the axial direction along the helix. However, with a further increase in size, the particles may start to settle and can be transported through rolling and gliding along the tube wall. For this mechanism of triboelectric charging, Li et al. [48] provided a conceptual framework. From their investigation, it can be concluded that, for particle sizes below $100 \mu \mathrm{m}$, triboelectrification by rolling contributes only a few percent of the collision charging.

\subsection{Net Charge-Material Dependence}

The triboelectrification of particles is influenced by the mechanical properties of the contact partners, as well as the (effective) electron work function. Particles of various materials should charge differently under otherwise identical conditions to promote sorting.

When a steel helix is utilized, the magnitude of specific charge changes by a factor of about four for pure triboelectric charging (see Figure 6a-y-axis intercept), while the PZNC value remains almost constant. Different intersections with the $x$-axis (PZNC) only indicate differences in the $\Delta \Phi$ (cf. Equation (1)), whereas the intersection with the $y$-axis results from a different charging efficiency, combined with a different $\Delta \Phi$. The PZNC for both helix materials vary only slightly, indicating that the work functions of the two wall materials are close to each other.
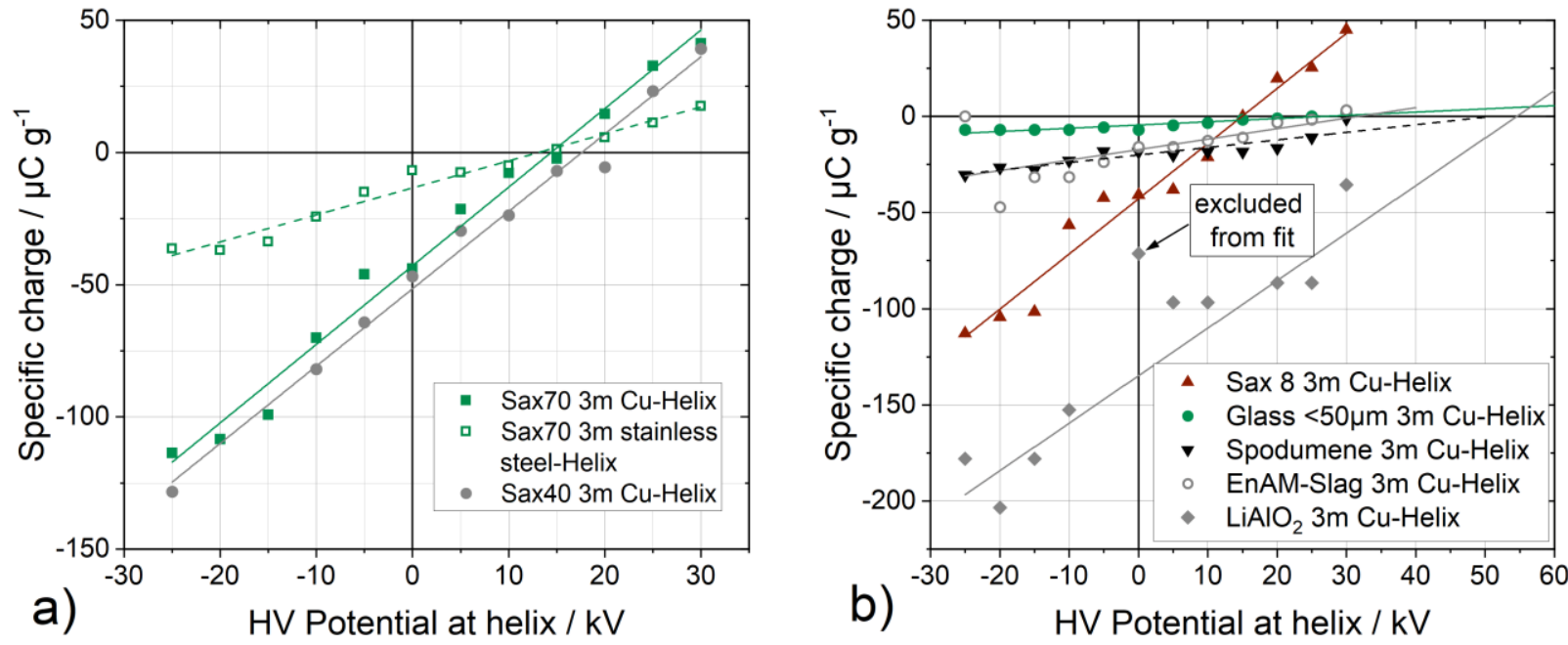

Figure 6. (a) Net charge for combinations of limestone with different helix materials (copper and steel). (b) Net charges for combinations of different particle materials with the copper helix. Uncertainties in the slope and the PZNC values for the different materials are: Sax 70: Slope: $\pm 13 \%$, PZNC: $\pm 9 \%$; Sax 40: Slope: $\pm 12 \%$, PZNC: $\pm 9 \%$; Sax 8: Slope: $\pm 0.17 \%$, PZNC: $\pm 0.45 \%$; Glass: Slope: $\pm 11 \%$, PZNC: $\pm 17 \%$; Lithium aluminate.: Slope: $\pm 50 \%$, PZNC: $\pm 6 \%$; Spodumene: Slope: $\pm 1 \%$, PZNC: $\pm 10 \%$.

A change in the charging efficiency $(\mathrm{kc})$ could be due to differences in the mechanical properties of the contacting wall, like the Poisson ratio and Young modulus of steel (Poisson ratio $=0.3 ; \mathrm{E}=210 \mathrm{GPa}$ ) or copper $($ Poisson ratio $=0.35 ; \mathrm{E}=125 \mathrm{GPa})$ ). In the case of a Hertzian contact between two smooth components, many factors, including the Young's modulus, particle density, particle diameter, and impact velocity, determine the contact area. Assuming constant impaction velocities of the limestone particles on copper and steel walls, and taking the different material properties into account, the difference in the contact area amounts to only about $5 \%$ (calculated by the formula of Li et al. [48] and with 
a Poisson ratio and Young modulus of limestone of $0.27 \mathrm{GPa}$ and $50 \mathrm{GPa}$, respectively). Therefore, the minor differences in the mechanical behavior of the walls alone cannot explain the observed huge discrepancy in the charging behavior (factor of three). Another factor influencing the electrification in two ways is the surface roughness, since the effective contact area is influenced by it [51]. Roughness measurements of the inner copper and steel pipe surfaces after the experiments were performed. It was found that the roughness of the two materials differed by a factor of about two $\left(\mathrm{R}_{\mathrm{Z} \text {,copper }}=3.165 \mu \mathrm{m} ; \mathrm{R}_{\mathrm{Z} \text {,steel }}=1.489 \mu \mathrm{m}\right)$, which may result in different charging efficiencies and, thus, different slopes in the forced triboelectrification. In addition, it was shown that the turbulent deposition of the finest particles increased with the increasing roughness, resulting in an upward shift to higher deposition velocities in Figure 5b [52].

The triboelectric charging of other powders, such as artificial slag, spodumene, lithium aluminate $\left(\mathrm{LiAlO}_{2}\right)$, and glass beads, confirmed the material dependence of the PZNC (cf. Figure $6 \mathrm{~b}$ ). For example, the PZNC of Saxolith 70 is approximately $16 \mathrm{kV}$, while that of lithium aluminate is roughly $55 \mathrm{kV}$. The PZNC of the spodumene is between the PZNC of the glass spheres and lithium aluminate, indicating its material dependence due to the significant $\mathrm{SiO}_{2}$ content $(64.7 \mathrm{wt} \%)$ in it. Due to a small content of calcium and several minerals, the EnAM slag has a lower PZNC than lithium aluminate but higher than limestone. These findings point to a repeatable and predictable material dependence, which is a requirement for sorting procedures.

\subsection{Characterization of the Charge Distribution}

The electrostatic precipitator (ESP) was used to investigate the fractions of neutral and charged particles. While charged particles are deposited on the electrodes, the neutral particles flow through the ESP and are collected by a cyclone. According to Hansen et al. [37], $80 \%$ of low-charged Talcum particles of similar particle size distributions were deposited in the same ESP and operated at identical conditions (mass loading, air flow, and electric field). Therefore, it is assumed that nearly $100 \%$ of the higher-charged limestone particles are deposited.

The length of the copper helix and applied high voltage were varied to investigate the effect on the mass fractions of the neutral and charged particles. In Figure 7, the mass fractions of the positively charged, negatively charged, and neutral Sax 8 particles for a helix length of $3.0 \mathrm{~m}$ are shown for several applied potentials (Figure $7 \mathrm{~b}$ ). In addition, the different charge fractions without the helix are also included in Figure 7a and indicated in Figure 8 as helix length $=0 \mathrm{~m}$. The highest fraction of the neutral particles was found at a potential of $+16 \mathrm{kV}$, i.e., at the PZNC. Starting from the most negative voltage towards the PZNC, the neutral fraction increased almost linearly, while the positive and negative fractions decreased in the same manner. Above the PZNC, the positive and negative fractions increased with increasing the applied potential, greatly reducing the amount of neutral particles. Further investigations for other helix lengths and applied potentials are shown in Appendix C (Figure A1).

By changing the lengths of the helix, another interesting effect occurs. Without applied potential, the neutral fraction increases with the helix length from $20 \%$ to $46 \%$, whereas, at the PZNC $(+16 \mathrm{kV})$, nearly $70 \%$ was reached (cf. Figure 8$)$. The investigated method may increase the sorting efficiency by appr. 50\% for a given helix length by applying the potential corresponding to the PZNC. While the amount of charged particles decreases equally for both signs for pure tribocharging, the fraction of negatively charged particles decreases more than the positively charged particles at the PZNC.

The main goal of this investigation was to neutralize the majority of the particles with an external potential. At the PZNC, this high neutral fraction was generated, indicated by the charge distributions. In future investigations, this mechanism will be applied in a sorting apparatus, where the charging process of a mixture of two materials can be influenced before the sorting process, leading to a better enrichment ratio. 


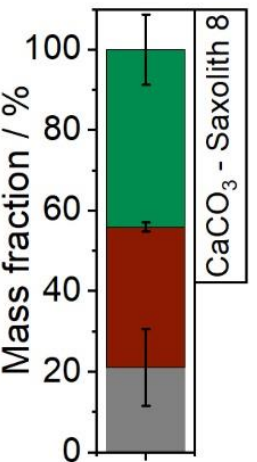

Dispering unit, without helix

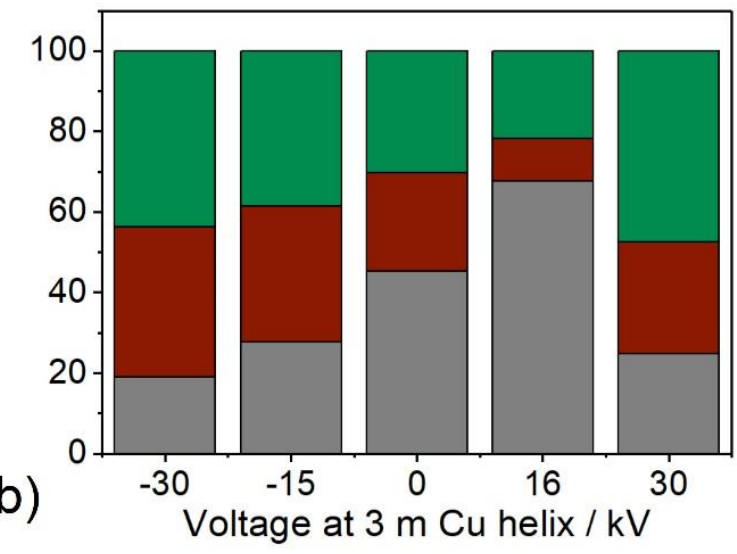

Figure 7. Charged and neutral fractions of Saxolith 8 for (a) no helix attached (b) a 3-m copper helix attached.

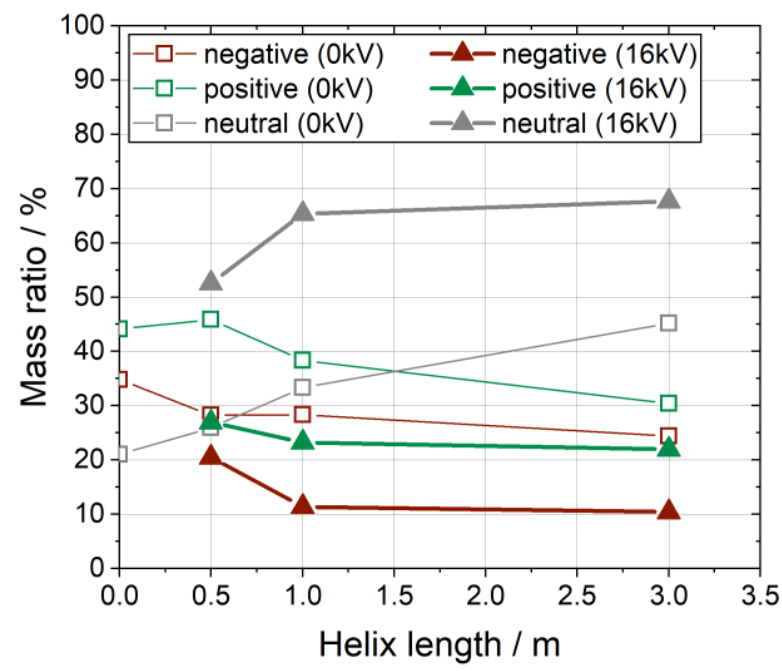

Figure 8. Charged and neutral mass fractions of the particles with no external potential $(0 \mathrm{kV})$ and potential at the PZNC $(16 \mathrm{kV})$ of Saxolith.

\section{Conclusions}

Experiments focused on actively influencing the triboelectric charge of powders were conducted. The particles were dispersed by a dry dispersing unit before being led through a coiled copper or steel pipe. The investigated particulate materials were isolators of different effective work functions and various mean diameters, ranging from roughly $3.5 \mu \mathrm{m}$ to $60 \mu \mathrm{m}$. The main objective was to influence the triboelectrification (with an external, electrical potential) so that a high fraction of neutralized particles was obtained. For a multicomponent material sorting process, the neutral fraction was the only possibility to reduce the problem of equal mobility and to increase the sorting efficiency. In general, triboelectric charging leads to bipolar charge distributions, and thus, the target material should ideally be neutral while the tailings are charged and, hence, easily removable in an electrostatic precipitator. Through the applied voltage, the particle net charge could be adjusted, also resulting in the highest neutral fraction at the Point of Zero Net Charge (PZNC), which is material-dependent. This observation can be used to concentrate, e.g., lithium aluminate, in a material-sorting process.

If the work functions of two materials are close to one another, separation by the materials' triboelectric charges is hardly possible, as well as the application of the shown method here. However, different dependencies on the external potential (slopes) may result in different particle charging away from the PZNC. Then, for a voltage away from 
the PZNC, triboelectric charging combined with electrostatic precipitation could still be used for particle sorting - however, with a lower sorting efficiency (i.e., reduced enrichment). In this case, an improvement of the separation efficiency may be achieved using a cascading process.

The investigation of limestone particles showed that the bipolarity could not be fully suppressed but significantly decreased at the PZNC, independent from the pipe length. However, the pipe length affects the slope of the relation between the net charge vs. applied potential. For limestone particles larger than about $7 \mu \mathrm{m}$ (Sax 8, Sax 40, and Sax70), the mass-specific net charge of the particles was more dependent on the contact partner than on the particle size. For small limestone particles (Sax 2, mean: $3.5 \mu \mathrm{m}$ ), the specific net charge was greatly reduced, presumably due to their low inertia in the turbulent flow.

Finally, the comparison of different pipe materials with similar work functions underlined the importance of surface roughness affecting the effective contact area and, hence, the intensity of the charge transfer.

For technical applications, one parameter must be taken into account that has not been considered here, namely the relative humidity. In the present study, only dried powders and dried air were used, which may be difficult in industrial applications. The influence of the relative humidity on triboelectric charging can be significant, as shown by Oberrauner et al. [40].

Author Contributions: Conceptualization, L.H. and M.W.; methodology, L.H. and M.W.; formal analysis, L.H., M.W., and A.W.; investigation, L.H. and M.W.; resources, A.P.W.; writing-original draft preparation, L.H. and M.W.; writing—review and editing, A.W. and A.P.W.; visualization, L.H. and M.W.; supervision, A.P.W.; project administration, A.W.; and funding acquisition, A.P.W. All authors have read and agreed to the published version of the manuscript.

Funding: This research was funded by the German Research Foundation (DFG), grant number WE 2331/22-2. The publishing fee of the article was funded by the Open Access Publishing Fund of Clausthal University of Technology.

Data Availability Statement: The data is available on reasonable request from the corresponding author.

Acknowledgments: We want to thank Theresa Rimbach, Mirco Dreeßen, and Silvia Löffelholz (IEC) for their help during the experimental investigations.

Conflicts of Interest: The authors declare no conflict of interest. The funders had no role in the design of the study; in the collection, analyses, or interpretation of the data; in the writing of the manuscript; or in the decision to publish the results.

\section{Appendix A. Approximation of the Work Function of Lithium Aluminate}

In the literature, values for the electron work function of lithium aluminate $\left(\mathrm{LiAlO}_{2}\right)$ are not available. Therefore, measurements were conducted using self-produced $\mathrm{LiAlO}_{2}$ nanoparticles. The particles were generated by nebulizing a solution of lithium nitrate and $\alpha$-aluminum nitrate, followed by a calcination step at $1000{ }^{\circ} \mathrm{C}$ within a tube furnace. The work function of these $\mathrm{LiAlO}_{2}$ particles was above the upper limit of $8.5 \mathrm{eV}$ of the employed home-built measurement system (Aerosol Photoemission Spectroscopy-APES) developed by Röhrbein [53]: Therefore, a work function $>8.5 \mathrm{eV}$ was assumed.

\section{Appendix B. Turbulent Deposition}

In a turbulent pipe flow, particles are deposited if they pass the laminar and viscous boundary layer at the wall of the pipe due to their inertia. To determine the deposition rate by Wood [54] (Equation (A3)), the (dimensionless) relaxation time is needed (Equation (A1)):

$$
\tau_{a e}{ }^{+}=\frac{\tau_{a e} \cdot u^{* 2}}{v_{a i r}} \text { with }: \tau_{a e}=\frac{\rho_{p} \cdot d_{p}{ }^{2}}{18 \eta} u^{*}=\bar{u} \cdot \sqrt{\frac{f}{8}} f=\frac{0.316}{\sqrt[4]{R e}}
$$


The dimensionless relaxation time $\tau_{a e}{ }^{+}$is calculated by the kinematic viscosity of air $\left(v_{a i r}\right)$, the shear velocity $u^{*}$, and the relaxation time $\tau_{a e}$, where $\eta$ is the dynamic viscosity. The shear velocity itself is calculated by the friction factor $(f)$ and the average air velocity in the pipe $(\bar{u})$, which corresponds to the quotient of the wall shear stresses and the fluid density under the square root. It is also possible to simplify this calculation by using the friction factor by Schlichting [55], which is calculated with the fluid Reynolds number $(R e)$. The Schmidt number $(S c)$ can be calculated by Equation (A2) [56], where the Stokes-Einstein equation gives the mass diffusivity $(D)$ of a particle, and $C_{C}$ is the Cunningham correction.

$$
\begin{gathered}
S c=\frac{v}{D}=\frac{3 \pi \eta d_{p} v}{k T C_{c}} \\
u_{d}^{+}=0.057 S c^{-\frac{2}{3}}+4.5 \cdot 10^{-4} \tau_{a e}{ }^{2}
\end{gathered}
$$

\section{Appendix C. Charge Distributions for Shorter Helix Lengths}

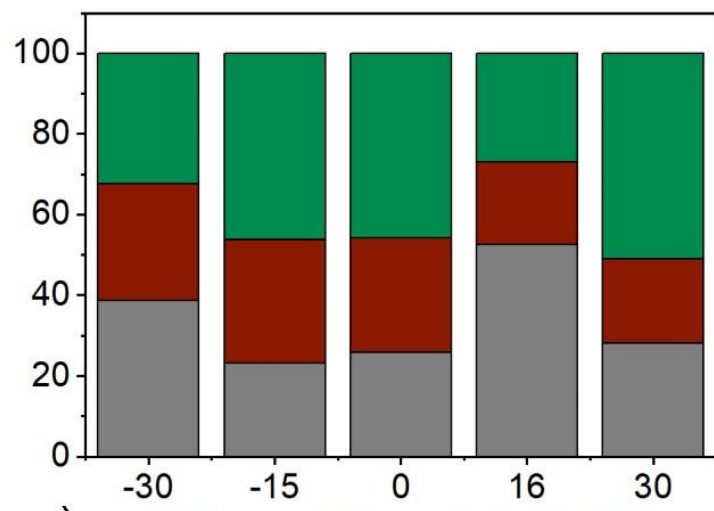

a) Voltage at $0.5 \mathrm{~m} \mathrm{Cu}$ helix / $\mathrm{kV}$

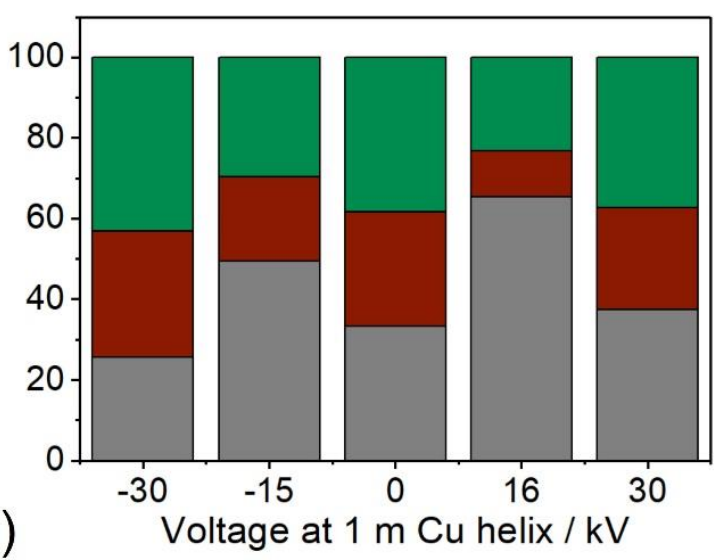

b)

Figure A1. Charged (positive: green bars, negative: red bars) and neutral fractions (grey bars) of Saxolith 8 for (a) 0.5-m copper helix attached and (b) 1-m copper helix attached.

\section{References}

1. Kim, D.; Jin, I.K.; Choi, Y.K. Ferromagnetic nanoparticle-embedded hybrid nanogenerator for harvesting omnidirectional vibration energy. Nanoscale 2018, 10, 12276-12283. [CrossRef] [PubMed]

2. Kim, I.; Roh, H.; Yu, J.; Jeon, H.; Kim, D. A triboelectric nanogenerator using silica-based powder for appropriate technology. Sens. Actuators A Phys. 2018, 280, 85-91. [CrossRef]

3. Vivekananthan, V.; Chandrasekhar, A.; Alluri, N.R.; Purusothaman, Y.; Khandelwal, G.; Pandey, R.; Kim, S.J. Fe $2 \mathrm{O}_{3}$ magnetic particles derived triboelectric-electromagnetic hybrid generator for zero-power consuming seismic detection. Nano Energy 2019, 64, 103926. [CrossRef]

4. Kim, D.; Oh, Y.; Hwang, B.W.; Jeon, S.B.; Park, S.J.; Choi, Y.K. Triboelectric nanogenerator based on the internal motion of powder with a package structure design. ACS Nano 2016, 10, 1017-1024. [CrossRef]

5. Peretti, R.; Serci, A.; Zucca, A. Electrostatic K-feldspar/Na-feldspar and feldspar/quartz separation: Influence of feldspar composition. Miner. Process. Extr. Metall. Rev. 2012, 33, 220-231. [CrossRef]

6. Dwari, R.K.; Hanumantha Rao, K. Non-coking coal preparation by novel tribo-electrostatic method. Fuel 2008, 87, 3562-3571. [CrossRef]

7. Bittner, J.D.; Hrach, F.J.; Gasiorowski, S.A.; Canellopoulus, L.A.; Guicherd, H. Triboelectric belt separator for beneficiation of fine minerals. Procedia Eng. 2014, 83, 122-129. [CrossRef]

8. Zou, H.; Guo, L.; Xue, H.; Zhang, Y.; Shen, X.; Liu, X.; Wang, P.; He, X.; Dai, G.; Jiang, P.; et al. Quantifying and understanding the triboelectric series of inorganic non-metallic materials. Nat. Commun. 2020, 11, 2093. [CrossRef]

9. Biegaj, K.W.; Rowland, M.G.; Lukas, T.M.; Heng, J.Y.Y. Surface Chemistry and Humidity in Powder Electrostatics: A Comparative Study between Tribocharging and Corona Discharge. ACS Omega 2017, 2, 1576-1582. [CrossRef]

10. Pan, S.; Zhang, Z. Fundamental theories and basic principles of triboelectric effect: A review. Friction 2019, 7, 2-17. [CrossRef]

11. Manouchehri, H.R.; Rao, K.H.; Forssberg, K.S.E. Triboelectric charge, electrophysical properties and electrical beneficiation potential of chemically treated feldspar, quartz and wollastonite. Magn. Electr. Sep. 2002, 11, 9-32. [CrossRef] 
12. Ciccu, R.; Ghiani, M.; Ferrara, G. Selective Tribocharging of Particles for Separation. KONA Powder Part. J. 1993, 11, 5-16. [CrossRef]

13. Wang, Z.L.; Wang, A.C. On the origin of contact-electrification. Mater. Today 2019, 30, 34-51. [CrossRef]

14. Kelly, E.G.; Spottiswood, D.J. The theory of electrostatic separations: A review part III. The separation of particles. Miner. Eng. 1989, 2, 337-349. [CrossRef]

15. Harper, W.R. The Volta effect as a cause of static electrification. Proc. R. Soc. Lond. Ser. A Math. Phys. Sci. 1951, 205, 83-103. [CrossRef]

16. Matsusaka, S.; Oki, M.; Masuda, H. Bipolar charge distribution of a mixture of particles with different electrostatic characteristics in gas-solids pipe flow. Powder Technol. 2003, 135-136, 150-155. [CrossRef]

17. Lacks, D.J.; Mohan Sankaran, R. Contact electrification of insulating materials. J. Phys. D Appl. Phys. 2011, 44, 453001. [CrossRef]

18. Lowell, J.; Rose-Innes, A.C. Contact electrification. Adv. Phys. 1980, 29, 947-1023. [CrossRef]

19. McCarty, L.S.; Whitesides, G.M. Electrostatic charging due to separation of ions at interfaces: Contact electrification of ionic electrets. Angew. Chem. Int. Ed. 2008, 47, 2188-2207. [CrossRef]

20. Harper, W.R. Contact and Frictional Electrification, 1st ed.; Jackson, W., Fröhlich, H., Mott, N.F., Eds.; Oxford University Press: Oxford, UK, 1967; Volume 1.

21. Kwetkus, B.A.; Sattler, K. Electrification Curves. J. Phys. D Appl. Phys. 1992, 25, 1400-1408. [CrossRef]

22. Musa, U.G.; Cezan, S.D.; Baytekin, B.; Baytekin, H.T. The Charging Events in Contact-Separation Electrification. Sci. Rep. 2018, 8, 2472. [CrossRef] [PubMed]

23. Mirkowska, M.; Kratzer, M.; Teichert, C.; Flachberger, H. Principal Factors of Contact Charging of Minerals for a Successful Triboelectrostatic Separation Process-A Review. BHM Berg Hüttenmännische Mon. 2016, 161, 359-382. [CrossRef]

24. Ema, A.; Yasuda, D.; Tanoue, K.I.; Masuda, H. Tribo-charge and rebound characteristics of particles impact on inclined or rotating metal target. Powder Technol. 2003, 135-136, 2-13. [CrossRef]

25. Bierwirth, M.; Gensch, M.; Weber, A.P. Influence of the Impaction Angle on the Triboelectric Charging of Aerosol Nanoparticles Chem. Ing. Tech. 2021, 93, 1316-1322. [CrossRef]

26. Baytekin, H.T.; Patashinski, A.Z.; Branicki, M.; Baytekin, B.; Soh, S.; Grzybowski, B.A. The mosaic of surface charge in contact electrification. Science 2011, 333, 308-312. [CrossRef] [PubMed]

27. Kronik, L.; Shapira, Y. Surface photovoltage phenomena: Theory, experiment, and applications. Surf. Sci. Rep. 1999, 37, 1-206. [CrossRef]

28. Matsusaka, S.; Maruyama, H.; Matsuyama, T.; Ghadiri, M. Triboelectric charging of powders: A review. Chem. Eng. Sci. 2010, 65, 5781-5807. [CrossRef]

29. Ireland, P.M. Triboelectrification of particulate flows on surfaces: Part II-Mechanisms and models. Powder Technol. 2010, 198, 199-210. [CrossRef]

30. Fomenko, V.S.; Samsonov, G.V. Handbook of Thermionic Properties, 1st ed.; Plenum Press Data Division: New York, NY, USA, 1966; ISBN 9781468472950.

31. Wang, X.Y.; Li, D.Y. Mechanical, electrochemical and tribological properties of nano-crystalline surface of 304 stainless steel. Wear 2003, 255, 836-845. [CrossRef]

32. Guo, L.; Hua, G.; Yang, B.; Lu, H.; Qiao, L.; Yan, X.; Li, D. Electron work functions of ferrite and austenite phases in a duplex stainless steel and their adhesive forces with AFM silicon probe. Sci. Rep. 2016, 6, 20660. [CrossRef]

33. Mao, B.H.; Crumlin, E.; Tyo, E.C.; Pellin, M.J.; Vajda, S.; Li, Y.; Wang, S.D.; Liu, Z. In situ study of the electronic structure of atomic layer deposited oxide ultrathin films upon oxygen adsorption using ambient pressure XPS. Catal. Sci. Technol. 2016, 6, 6778-6783. [CrossRef]

34. Etxebarria, A.; Koch, S.L.; Bondarchuk, O.; Passerini, S.; Teobaldi, G.; Muñoz-Márquez, M.Á. Work Function Evolution in Li Anode Processing. Adv. Energy Mater. 2020, 10, 2000520. [CrossRef]

35. Ullah, S.; Wan, G.; Kouzios, C.; Woodgate, C.; Cattelan, M.; Fox, N. Structure and electronic properties of tin monoxide (SnO) and lithiated SnO terminated diamond $\left(\begin{array}{lll}1 & 0 & 0\end{array}\right)$ and its comparison with lithium oxide terminated diamond. Appl. Surf. Sci. 2021, 559, 149962. [CrossRef]

36. Lacks, D.J.; Duff, N.; Kumar, S.K. Nonequilibrium accumulation of surface species and triboelectric charging in single component particulate systems. Phys. Rev. Lett. 2008, 100, 188305. [CrossRef]

37. Hansen, L.; Wollmann, A.; Weers, M.; Benker, B.; Weber, A.P. Triboelectric charging and separation of fine powder mixtures. Chem. Eng. Technol. 2020, 43, 933-941. [CrossRef]

38. Lee, V.; James, N.M.; Waitukaitis, S.; Jaeger, H.M. Collisional charging of individual sub-millimeter particles: Using ultrasonic levitation to initiate and track charge transfer. Phys. Rev. Mater. 2018, 2, 035602. [CrossRef]

39. Linsenbühler, M. Herstellung und Charakterisierung Funktionalisierter Composite-Partikel. Ph.D. Thesis, Friedrich-Alexander University Erlangen-Nuremberg, Erlangen, Germany, 2005.

40. Oberrauner, A.; Flachberger, H. Beitrag zur Untersuchung der triboelektrischen Aufladecharakteristik feindisperser KörnerschwärmeInvestigating the Triboelectric Charging Behaviour of Fine Powders. BHM Berg Hüttenmännische Mon. 2010, 155, 565-570. [CrossRef]

41. Shen, X.; Wang, A.E.; Sankaran, R.M.; Lacks, D.J. First-principles calculation of contact electrification and validation by experiment. J. Electrostat. 2016, 82, 11-16. [CrossRef] 
42. Wang, A.E. Driving Forces for the Triboelectric Charging of Well-Defined Insulated Material Surfaces. Ph.D. Thesis, Case Western Reserve University, Cleveland, OH, USA, 2020.

43. Matsusaka, S. Control of particle tribocharging. KONA Powder Part. J. 2011, 29, 27-38. [CrossRef]

44. Liu, B.Y.H.; Agarwal, J.K. Experimental observation of aerosol deposition in turbulent flow. J. Aerosol Sci. 1974, 5. [CrossRef]

45. Kallio, G.A.; Reeks, M.W. A numerical simulation of particle deposition in turbulent boundary layers. Int. J. Multiph. Flow 1989, 15, 433-446. [CrossRef]

46. Grosshans, H.; Papalexandris, M.V. Numerical study of the influence of the powder and pipe properties on electrical charging during pneumatic conveying. Powder Technol. 2017, 315, 227-235. [CrossRef]

47. John, W.; Reischl, G.; Devor, W. Charge transfer to metal surfaces from bouncing aerosol particles. J. Aerosol Sci. 1980, 11, 115-138. [CrossRef]

48. Li, J.; Yao, J.; Zhao, Y.; Wang, C.H. Large eddy simulation of electrostatic effect on particle transport in particle-laden turbulent pipe flows. J. Electrostat. 2021, 109, 103542. [CrossRef]

49. Friedlander, S.K. Smoke, Dust, and Haze: Fundamentals of Aerosol Dynamics, 2nd ed.; Oxford University Press: Oxford, UK, 2000; ISBN 0-19-512999-7.

50. Noorani, A.; Sardina, G.; Brandt, L.; Schlatter, P. Particle transport in turbulent curved pipe flow. J. Fluid Mech. 2016, 793, 248-279. [CrossRef]

51. Wang, H.; Fotovat, F.; Bi, X.T.; Grace, J.R. Tribo-charging of binary mixtures composed of coarse and fine particles in gas-solid pipe flow. Particuology 2019, 43, 101-109. [CrossRef]

52. Guha, A. Transport and deposition of particles in turbulent and laminar flow. Annu. Rev. Fluid Mech. 2008, 40, 311-341. [CrossRef]

53. Röhrbein, J.; Weber, A.P. A system for on-line characterization of gas-borne particle surface properties based on their photoemission. J. Aerosol Sci. 2018, 120, 82-91. [CrossRef]

54. Wood, N.B. A simple method for the calculation of turbulent deposition to smooth and rough surfaces. J. Aerosol Sci. 1981, 12, 275-290. [CrossRef]

55. Schlichting, H.; Gersten, K. Grenzschicht-Theorie, 9th ed.; Springer: Berlin/Heidelberg, Germany; New York, NY, USA, 1997; ISBN 978-3-662-07555-5.

56. Fan, F.G.; Ahmadi, G. A sublayer model for turbulent deposition of particles in vertical ducts with smooth and rough surfaces. J. Aerosol Sci. 1993, 24, 45-64. [CrossRef] 